\title{
Reproducibility of the Dunlop Test for Motor Ocular Dominance Stability Among Young Saudi Females
}

\author{
MANA A. ALANAZI, Ph.D. \\ The Department of Optometry, College of Applied Medical Sciences, King Saud University, Riyadh, Saudi Arabia
}

\begin{abstract}
Background: Dunlop test is reliable for assessing ocular dominance, however, its reproducibility never been tested.

Aim of Study: To determine the reproducibility of the Dunlop test for determination of ocular dominant stability and the effects of visual fatigue among young Saudi female.

Subjects and Methods: Fifty-three healthy females (range, 19-23 years) were assessed for sighting and motor ocular dominance using the hole-in-the-card test and Dunlop test, respectively. The Dunlop test was assessed twice in two different visits and was repeated the third time for a subgroup at the week's end to assess the effect of visual fatigue on stability of ocular dominance by using the visual discomfort scores (VDCS).
\end{abstract}

Results: The mean ( \pm standard deviation) $\log$ MAR visual acuity was similar for the right and left eyes. A significant proportion of the participants were right handed with right sighting eye dominance. There was no significant agreement between writing hand and sighting eye dominance; however, the Dunlop test results were in agreement with the hole-inthe-card test results. In total, $85 \%$ of the participants with right eye dominance on the Dunlop test had right sighting eye dominance. In total, $55.6 \%$ of those who had left motor eye dominance had left sighting eye dominance. Overall, $75.5 \%$ showed same eye dominance using both tests. Of the participants who showed right eye dominance in visit 1, all but one participant (93\%) showed the same eye dominance in visit 2, thus indicating a strong agreement between motor ocular dominance in the two visits. The mean VDCS was significantly greater in visit 3 than in visits 1 and 2 .

Conclusion: The sighting eye of female Saudi adults match their dominant hand in a majority of cases. Clinicians should be aware that the dominant eye for the same individual may differ depending on the test used. The stability of motor ocular dominance is unaffected by visual fatigue and the Dunlop test gives reproducible results for ocular dominance determination.

Key Words: Visual discomfort-Visual fatigue - Dunlop test - Binocular vision - Hole in the card test - Ocular dominance.

Correspondence to: Dr. Mana A. Alanazi, E-Mail: amana@ksu.edu.sa

\section{Introduction}

THE ocular dominance is defined as the tendency to prefer visual input from one eye over the other, both in fixation and in attention or in perceptive function $[1,2]$. Ocular dominance is important in close distance viewing [3] and is unrelated to spherical equivalent refraction in normal people [4]. The dominant eye shows greater accommodative response during binocular viewing [5] and based on the assumption that it is easier to suppress blur in non-dominant eye, the dominant eye is usually corrected for distant vision while the non-dominant eye is corrected for near vision particularly in monovision design [6]. The success of monovision correction in presbyopia demonstrates the impact of ocular dominance on visual outcomes [6].

Ocular dominance has multiple dimensions [7] such that the dominant eye in a sighting test may not be the same as that in a rivalry or motor test. According to Evans [8], ocular dominance can be subdivided into sighting, motor, and sensory. Sighting dominance $[\mathbf{1 , 2}]$ refers to the preferential use of one eye during target fixation and is commonly measured using the hole-in-the-card test $[10,11]$ Sensory dominance occurs when the perception of a stimulus to one eye dominates the other in retinal rivalry conditions and can be attributed to an interocular imbalance of the underlying inhibitory neural mechanism. Motor dominance involves binocular conflict and can be measured by the Dunlop test which was used by Stein group [12]

Handedness is associated with cerebral lateralization of language. Visual cortices tend to prefer visual input from the dominant eye over the nondominant eye [13]. Despite numerous studies on ocular dominance, its function and its association with handedness remains controversial [7]. Although 
studies have shown that Dunlop test is reliable for assessing ocular dominance [7], its reproducibility has not been investigated. Additionally, studies investigating the stability of ocular dominance as determined by the Dunlop test have yielded different results [13]. The results of ocular dominance by Dunlop test is largely dependent on the participant's intelligence. Therefore, this study was designed to investigate: (a) The reproducibility of the Dunlop test for the assessment of ocular dominance stability; (b) The effect of naturally induced visual fatigue (during week days) on the stability of motor ocular dominance; (c) The frequency of crossed or un-crossed eye/hand dominance; and (d) The consistency between sighting ocular dominance (determined with the hole-in-the-card test) and the motor ocular dominance (determined with the Dunlop test) in healthy adults of Saudi origin.

\section{Subjects and Methods}

This study was conducted at King Saud University, Riyadh, Saudi Arabia during the period from February 2019 to June 2019.

\section{Ethics:}

Approval for the study was obtained from the Research Ethics committee of College of Applied Medical Sciences prior to data collection. The study protocol followed the tenets of the Declaration of Helsinki of the World Medical Association regarding scientific research on human subjects. Informed consent was obtained from all participants.

\section{Subjects:}

Fifty-three female participants (mean age $20.5 \pm 1.0$ years; range, $19-23$ years) were recruited from optometry students of King Saud University. All participants underwent a complete ophthalmic examination and ascertainment of ocular and hand dominance including visual acuity (VA) measurement with best correction using the logMAR chart.

\section{Exclusion and inclusion criteria:}

The inclusion criteria were as follows: Participants $\leq 30$ years of age, with normal binocular vision, no asthenopic visual symptoms, orthophoria determined by the cover test, distance visual acuity better than or equal to 20/22 (6/6.7) in the two eyes (i.e. the absence of amblyopia), distance phoria between 2-4 exo with the Synoptophore (determined as the prism power obtained by turning the tubes of the Synoptophore to produce a comfortable single image of the fusion slides), normal sterioacuity test results of 40 of arc using the Titmus fly test.
Participants were excluded from this study if they had any of the following conditions: Anisometropia (interocular refraction difference $\geq 2.00$ D), VA worse than $20 / 25$, unequal visual acuity between eyes (more than one line), history of migraine or severe headaches or photosensitive epilepsy, history of strabismus or ptosis, history of ocular surgery including cataract or refractive surgery, any clinically significant retinal pathology, glaucoma, optic neuropathy, optic disc anomalies or other diseases that might affect visual acuity after correction and the presence of marked facial asymmetry.

\section{Study protocol and procedures:}

Physical or ocular health related symptoms were determined for every participant via a questionnaire. Using the visual discomfort scores (VD$\mathrm{CS}$ ), visual fatigue was assessed at the beginning of each visit and was used to exclude participants with asthenopia. Ocular dominance was determined using the hole-in-the-card test (Dolman method) and Dunlop test for assessing motor ocular dominance and its stability. Hand dominance was ascertained by asking each participant all are females/her handedness, especially for near-work activity such as writing, using a hammer or a screwdriver, and using chopsticks when eating.

All participants attended the clinic twice (visits separated by one week). During the second visit, only the Dunlop test was conducted to assess reproducibility of the measurements. Visual discomfort was evaluated before Dunlop test using VDCS at every visit and the scoring ranged from ' 0 ' for comfortable to '4' for uncomfortable. A subgroup of participants $(n=30)$ who presented for the test at day 1 of the week on visits 1 and 2, were further tested for the third time with the Dunlop test at the end of the week to assess the effects of fatigue on ocular dominance stability.

Hole-in-the-card test method for sighting ocular dominance assessment:

Hole-in-the-card test was used to determine sighting ocular dominance (Dolman method) [4] Holding a card with a hole in the middle using both hands, the participants were asked to view a 6-m distance target through their habitual corrections. The clinician (MA) occluded participant's each eye alternately and the participant was asked to identify the eye aligning with the hole and the target. The aligned eye was then considered as the dominant eye. The participant was later asked to move the card slowly toward the face while maintaining alignment with the fixation point until the hole was over an eye, which was considered the 
dominant eye. If no clear preference was observed, ocular dominance was recorded as undetermined.

\section{Dunlop test method for motor ocular dominance assessment:}

Dunlop test determined the motor ocular dominance and its stability. The stimuli used consisted of two macular-sized fusion slides (reproductions of Clement Clarke F69 and F70). Each slide contained identical drawings of a small house that subtended a visual angle of $2.2^{\circ}$, each house having two windows, one roof and one door. A tree located on one side of the door provided the monocular cue. In one slide, there was a smaller tree located on the left, and in the other slide a larger tree was on the right side of the door. With the aid of the synoptophore, the slides were presented such that the participants perceived it as a single fused image. After five trials (i.e. halfway through the test), the slides were interchanged to prevent the participants from adapting to the response. We randomized the initial order of presentation of the two slides across participants. The participants were asked to fixate at the central square on the door and slowly but smoothly, the two tubes of the synoptophore were moved at about 1 to $2 \% / \mathrm{sec}$ to create a base in prism effect which required divergence to maintain single fusion. Ideally, participants would indicate that one of the two trees had moved before reaching the fusion break. Report of a movement of the tree presented to the left eye signified the existence of right dominance and vice versa. If the participants reported that the cues appeared to move simultaneously or if they could not observe any movement before the fusion breaks, their response was classified as "no ocular dominance" (i.e. neither right nor left). We performed ten trials in line with reported procedures [7,14]. Motor ocular dominance was considered to be stable, if ocular dominance was consistent and the participants continued fixation on the target for at least eight times or more, as indicated previously [7].

To assess the test-retest repeatability, the test was conducted twice and a group of participants $(n=30)$ were required to attend a third testing session to assess the effect of fatigue on ocular dominance stability induced during the week.

\section{Statistical analysis:}

Three of the recruited subjects were excluded, as they did not fulfil the inclusion criteria: Two had un-equal VA of more than two-line difference between the two eyes, and one showed large exophoria at distance on testing. Data analyses included 53 participants and were performed using the SPSS (version 16, SPSS Inc, Chicago, Illinois, USA) statistical program. A two-tailed $p$-value of $<0.05$ was considered to be significant. The assumption of normality of the data was assessed using the Shapiro-Wilk test. The Kappa statistic was used to assess the agreement between the two ocular dominance tests as well as between hand and ocular dominance and to assess test re-test repeatability of the Dunlop test method and the effect of the induced visual fatigue on stability of motor ocular dominance. The pattern of hand-ocular dominance was classified as "uncrossed" dominance (i.e. both right eye and hand or both left eye and hand dominance) or "crossed" dominance (i.e. left eye and right hand or right eye and left hand). The difference in visual discomfort scores between the second and third visits were compared using paired $t$-test for only the subgroup $(n=30)$. With a sample size of 53 , the study had sufficient power $(80 \%)$ to detect statistically significant difference between the non-dominant and dominant eyes.

\section{Results}

Table (1) shows the descriptive statistics (mean, standard deviations), proportions of participants, and the results of paired $t$-test and chi square for continuous and discrete variables, respectively for 53 participants. The mean ( \pm standard deviation) Log Mar VA was similar between the right and left eye $(p=0.42)$ and the mean heterophoria at distant was $-0.34 \pm 1.4$ prism diopters and mean stereoacuity measure was 40 seconds of arc.

\section{Sighting dominant eye/hand dominance:}

Distribution of eye (sighting) dominance and hand dominance are shown in Table (1). The majority of the participants $(92.5 \%, \mathrm{n}=49)$ were right handed with a few left handed participants $(7.5 \%$, $\mathrm{n}=4 ; p<0.0001)$. Significantly more participants showed right sighting eye dominance $(p<0.001)$.

Agreement between hand dominance and sighting ocular dominance:

Kappa test revealed no significant agreement between writing hand and sighting eye dominance (kappa $=0.003, p=0.98$ ). There was right eye-right hand dominance in $75.5 \%$ of the participants while $24.5 \%$ had left eye-right hand dominance. Table (1) shows the incidence of crossed and uncrossed eye-hand dominance amongst the group.

Agreement between motor ocular dominance and sighting ocular dominance tests:

Comparing the Dunlop test results with the hole-in-the-card tests, a significant agreement was found with a Kappa value of 0.35 ( $p=0.004)$. Amongst participants who demonstrated right 
motor eye dominance ( $\mathrm{n}=41$ ), $85 \%$ had right sighting eye dominance and of those who had left motor eye dominance $(n=9), 55.6 \%$ had left sighting eye dominance. Overall, 40 of 53 participants (75.5\%) showed same eye dominance using both tests and for the three participants in whom the dominant eye could not be determined with the Dunlop test, one had right sighting eye dominance while two had left sighting eye dominance.

Table (1): Descriptive statistics of variables assessed in 53 female participants. Values are in mean \pm standard deviation or $\mathrm{n}(\%)$ where indicated.

\begin{tabular}{ll}
\hline Variable & Value \\
\hline Visual acuity, mean (SD), logMAR: & \\
RE & $0.01 \pm 0.03$ \\
LE & $0.01 \pm 0.07$
\end{tabular}

Dominant eyes by ocular

dominance tests:

Hole in the card, $n(\%)$ :

RE

$40(75.5)$

LE

$13(24.5)$

Dunlop test, $n(\%)$ :

RE (visits $1 \& 2$ )

LE (visits $1 \& 2$ )

Not determined (visits $1 \& 2$ )

Phoria, mean (SD), pd

$41(77.4) / 43(81.1)$

$9(17.0) / 10(18.9)$

$3(5.7 \%) / 0(0)$

$-0.34 \pm 1.4$

hand-ocular dominance:

Uncrossed dominance

Crossed dominance

$38(71.7)$

$15(28.3)$

IIEffect of weekdays on visual

discomfort scores (VDCS):

Visit one, mean \pm SD $\quad 0.23 \pm 0.50$

Scoring $=0, \mathrm{n}(\%)$

Scoring $=1, \mathrm{n}(\%)$

Scoring $=2, \mathrm{n}(\%)$

Visit two, mean (SD)

Scoring $=0, \mathrm{n}(\%)$

Scoring $=1, \mathrm{n}(\%)$

Scoring $=2, \mathrm{n}(\%)$

Visit three, mean (SD)

Scoring $=0, \mathrm{n}(\%)$

Scoring $=1, \mathrm{n}(\%)$

Scoring $=2, \mathrm{n}(\%)$

Scoring $=3, \mathrm{n}(\%)$

$24(80.0)$

$5(16.7)$

$1(3.3)$

$0.17 \pm 0.38$

$24(80.0)$

5 (16.7)

$1(3.3)$

$1.43(1.04)$

$7(23.3)$

8 (26.7)

$10(33.3)$

$5(16.7)$

SD : Standard deviation. RE : Right eyes.

PD : Prism diopter. LE : Left eye.

II : The data for only 30 participants were used.

\section{Test-retest repeatability of the dunlop test method:}

There was a strong agreement between motor ocular dominance response in the first and the second visits (Kappa value was $0.73, p<0.0005$ ). Of the 41 participants who showed right eye dominance $(77.3 \%)$ in visit 1 , all but one participant $(n=40,93.0 \%)$ showed the same eye dominance in visit 2 (Fig. 1). None of the participants showed the opposite eye dominance response in the second visit compared to the first visit and for those who were not able to determine a stable ocular dominance in the first visit $(5.7 \%, \mathrm{n}=3)$, they were able to determine the dominant eye at the second visit.

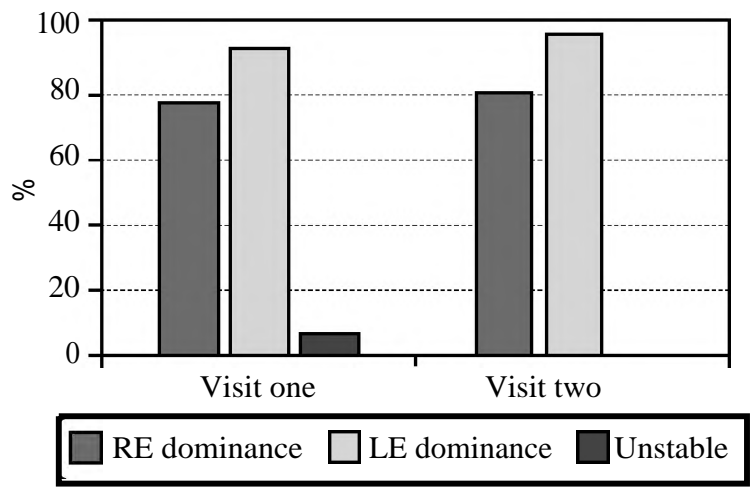

Fig. (1): Proportion of participants showing same eye dominance in visits 1 and 2 .

Comparison of VDCS between visits for the subgroup of patients:

The mean VDCS scores across the three visits are shown in Table (1). For the subgroup analysis of the 30 participants, the mean VDCS was significantly greater in visit 3 than in visit 1 (mean difference in VDCS scores, $1.20,95 \%$ CI: $1.53-$ $0.87 ; p<0.0005$ ) and in visit 2 (mean difference in VDCS scores, $1.27,95 \%$ CI: 1.63-0.90, $p<0.0005)$. In visit 1 , no participant reported feeling uncomfortable as compared to five participants $(16.7 \%)$ who felt some discomfort during visit 3.

Effect of the visual fatigue, induced during weekdays, on stability of the ocular dominance:

The agreement between motor ocular dominance responses (Kappa value was 0.73) in the group of subjects $(n=30)$ who performed Dunlop test at the beginning of the week and at the end of the same week approached significance (second and third visits, $p=0.05$ ). $91.7 \%$ versus $95.7 \%$ of participants showed right eye dominance in Visit 2 and 3 , respectively, whereas $83.3 \%$ of participants in both visits showed same left eye dominance. Fig. (2) shows the proportion of participants who showed stable and unstable eye dominance in the three visits. For these 30 participants, all those who showed stable eye dominance during the second visit maintained the same eye dominance in the third visit.

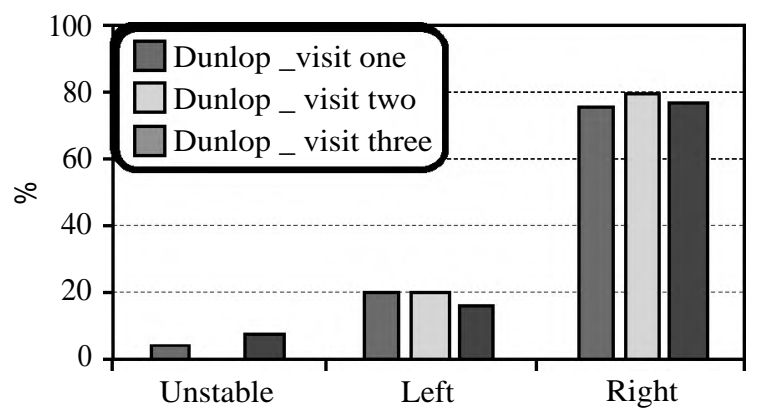

Fig. (2): Stability of eye dominance tested with the Dunlop test over three visits. 


\section{Discussion}

The study used two different test methods to investigate ocular dominance and its stability in young adults. There was a preponderance of right hand $(93 \%)$ and right eye $(76 \%)$ dominance among the participants and about $2 / 3 \mathrm{rd}$ of the participants showed uncrossed eye sighting/hand dominance. No significant agreement was found between writing hand and sighting eye dominance. Dunlop test demonstrated excellent repeatability for measuring motor ocular dominance with all but one participant. The high prevalence of right sighting ocular dominance has been largely reported in previous literatures with prevalence ranging from $62 \%$ [15] $63 \%$ [16], 65\% [17], 70\% [18], 78\% [19] to $88 \%$ [20] The finding provides additional evidence that the cyclopean eye (defined as the location in the head that serves as the origin for directional judgment of viewed objects [21]) in sighting dominance is slanted towards the right eye in most people [7].

In a meta-analysis investigating the relationship between handedness and eye dominance, the authors found that the proportion of right handed participants was $35 \%$ but $57 \%$ of those who were left handed had left eye dominance [22]. In this study, $93 \%$ of the participants were right handed but $76 \%$ of them had right eye dominance. For those who were left handed (7.5\%), $7.7 \%$ of them had left eye dominance. Along with no physiological evidence linking the dominant hand with the dominant eye, the lack of agreement between sighting eye and hand dominance is an indication of their independent correlation [23]. It has been suggested that handedness, as motor aspect, is represented contra laterally to the brain. However, retinal signals from each eye, as a sensory and motor component, are projected to both hemispheres of the brain, perceived, and interpreted binocularly and equally. The hemisphere laterality therefore, can include hand dominance but not eye dominance [17].

The strong agreement between the motor ocular dominance responses in both visits is in agreement with previous findings suggesting that the Dunlop test is a reliable method for determining ocular dominance and a valuable tool for investigating the development of vergence control [12]. Although many studies in the past have utilized Dunlop test to demonstrate the stability of ocular dominance and its association with reading skills $[12,14]$, only a few recent studies have demonstrated its application for motor ocular dominance stability [7]. In this study, few participants who could not identify a stable motor ocular dominance at the first visit were able to show stable ocular dominance in the second visit; and this may be attributed to a learning effect. However, in the second visit all participants showed stable motor ocular dominance.

Although there was a statistical significant agreement between the two ocular dominance tests, the association was weak with about $19 \%$ of participants showing a reverse in the preferred eye when one test was switched for the other. This inconsistency was greater among participants who showed left eye dominancy with the Dunlop test (44.4\% of them showed right eye dominancy with hole-in-the-card test) compared to those who showed right eye dominancy (14.6\% switched to left eye dominancy). This indicates that sighting and motor ocular dominance are independent conditions and this should be considered during optometry examination of ocular dominance as there could often be a single eye dominance for a given test $[\mathbf{1 , 2 4}]$. Consistency in determination of the sighting ocular dominant eye using different methods was reported previously by Walls [25], Porac and Coren [23] and more recently by Zeri [7] for different motor tests and sighting tests. A recent review suggested that only tests that allow for maintenance of binocular vision be used during the determination of ocular dominance if an accurate evaluation is to be made, since the visual system is designed to function binocularly [26], thus favoring the use of Dunlop test. A weak agreement between both ocular dominance tests suggests that clinicians should cautiously use the hole-inthe-card method to determine motor dominance.

Additionally, this study found that motor ocular dominance stability was unaffected by the visual fatigue which was suspected to be induced by the end of the week. The strong kappa test of agreement between visits 2 and 3 (Fig. 2) confirms that ocular dominance is a stable condition unaffected by the ocular motor status in adults with normal binocular vision $[\mathbf{1 , 1 6 , 2 3 ]}$

The limitation of the current study includes only young female studying at King Saud University in the City of Riyadh. Nevertheless, it proves that Dunlop test can be reproduced since female are more susceptible for visually induced fatigue compared to male [27]. Further study with a larger population that include both genders of different ages is still needed to establish the predictability of such test.

\section{Conclusion:}

The sighting eye of Saudi adult female students appear to match their dominant hand in majority 
of cases, however, the physiological basis for this remains unclear. For each individual, there appears to be a single sighting dominant eye that can be easily assessed and clinicians should be aware that the dominant eye for the same individual might differ depending on the test used for assessment. Saudi a femaledult students demonstrated stable motor ocular dominance that was unaffected by the visual fatigue and this can be reliably measured by Dunlop test method in a clinical setting.

\section{Acknowledgement:}

The author thanks the Deanship of Scientific Research and RSSU at King Saud University for their technical support.

\section{Competing interests:}

The author reports no conflicts of interest in this work.

\section{References}

1- MAPP A.P., ONO H. and BARBEITO R.: What does the dominant eye dominate? A brief and somewhat contentious review. Percept. Psychophys, 65 (2): 310-317, 2003.

2- LIN S.Y. and WHITE G.: Mandibular position and head posture as a function of eye dominance. J. Clin. Pediatr. Dent., 20 (2): 133-140, 1996.

3- DUNLOP P.: Development of dominance in the central binocular field. Br. Orthopt. J., 49: 31-35, 1992.

4- WANG Q., WU Y., LIU W. and GAO L.: Dominant eye and visual evoked potential of patients with myopic anisometropia. Biomed. Res. Int., 2016: 5064892, 2016.

5- VINCENT S.J., COLLINS M.J., READ S.A., et al.: The short term accommodation response to aniso accommodative stimuli in isometropia. Ophthalmic Physiol. Opt., 35 (5): 552-561, 2015.

6- NITTA M., SHIMIZU K. and NIIDA T.: The influence of ocular dominance on monovision the influence of strength of ocular dominance on visual functions. Nippon Ganka Gakkai Zasshi, 111 (6): 441-446, 2017.

7- ZERI F., DE LUCA M., SPINELLI D. and ZOCCOLOTTI P.: Ocular dominance stability and reading skill: A controversial relationship. Optom. Vis. Sci., 88 (11): 1353 1362, 2011.

8- EVANS B.J.: Visual Factors in Dyslexia. In: The Study of Dyslexia. Springer, pp 1-22, 2005.

9- ITO M., SHIMIZU K., KAWAMORITA T., ISHIKAWA H., SUNAGA K. and KOMATSU M.: Association between ocular dominance and refractive asymmetry. J. Refract. Surg., 29 (10): 716-720, 2013.

10- LINKE S.J., BAVIERA J., RICHARD G. and KATZ T.: Association between ocular dominance and spherical/astigmatic anisometropia, age, and sex: Analysis of 1274 hyperopic individuals. Invest. Ophthalmol. Vis. Sci., 53 (9): 5362-5369, 2012.
11-ESER I., SCHWENDEMAN F., DURRIE D.S. and STAHL J.E.: Association between ocular dominance and refraction. J. Refract. Surg., 24 (7): 685-689, 2008.

12- STEIN J., RICHARDSON A. and FOWLER M.: Monocular occlusion can improve binocular control and reading in dyslexics. Brain, 123 (1): 164-170, 2000.

13- YGGE J., LENNERSTRAND G., RYDBERG A., WIJECOON S. and PETTERSSON B.M.: Oculomotor functions in a Swedish population of dyslexic and normally reading children. Acta Ophthalmol., 71 (1): 10-21, 1993.

14- EVANS B.J., DRASDO N. and RICHARDS I.L.: Investigation of accommodative and binocular function in dyslexia. Ophthalmic Physiol. Opt., 14 (1): 5-19, 1994.

15- LINKE S.J., BAVIERA J., MUNZER G., STEINBERG J., RICHARD G. and KATZ T.: Association between ocular dominance and spherical/astigmatic anisometropia, age, and sex: Analysis of 10,264 myopic individuals. Invest. Ophthalmol. Vis. Sci., 52 (12): 9166-9173, 2011.

16- CHING C., YEN M., LIN H., HSIA W. and HSU W.: Association of ocular dominance and anisometropic myopia. Invest. Ophthalmol. Vis. Sci., 45 (8): 2856-2860, 2004.

17- PORTAL J.M. and ROMANO P.E.: Major review: Ocular sighting dominance: A review and a study of athletic proficiency and eye-hand dominance in a collegiate baseball. Binocul. Vis. Strabismus Q., 13 (2): 125-132, 1998.

18- ROBBOY M.W. and ERICKSON P.: Effects of sighting and sensory dominance on monovision high and low contrast visual acuity. CLAO J., 16 (4): 299-301, 1990.

19- DANE S. and GUMUSTEKIN K.: Correlation between hand preference and distance of focusing points of two eyes in the horizontal plane. Int. J. Neurosc., 112 (10): 1141-1147, 2002.

20- NUHU M.A., FATIMA T.N., OLUWAFERANMI H.L., et al.: Handednessm Eyedness, footedness, Crossed Dminance and Digital Rtio in Nigerian people. J. Res. Med. Dent. Sci., 6 (6): 62-69, 2018.

21- ERKELENS C.J. and VAN EE R.: The role of the cyclopean eye in vision: Sometimes inappropriate, always irrelevant. Vis. Res., 42 (9): 1157-1163, 2002.

22- BOURASSA D.C., MCMANUS I.C. and BRYDEN M.P. Handedness and eye dominance: A meta-analysis of their relationship. Laterality, 1 (1): 5-34, 1996.

23- PORAC C. and COREN S.: The dominant eye. Psychol. Bull., 83 (5): 880-897, 2002.

24- EHRENSTEIN W.H., ARNOLD-SCHULZ-GAHMEN B.E. and JASCHINSKI W.: Eye preference within the context of binocular functions. Graefes. Arch. Clin. Exp. Ophthalmol., 243 (9): 926-932, 2005.

25- WALLS G.L.: A theory of ocular dominance. AMA. Arch. Ophthalmol., 45 (4):387-412, 1951.

26- LABY D.M. and KIRSCHEN D.G.: Thoughts on ocular dominance-is it actually a preference? Eye. Contact. Lens, 37 (3):140-144, 2011.

27- PORCAR E., PONS A.M. and LORENTE A.: Visual and ocular effects from the use of flat-panel displays. Int. J. Ophthalmol., 9 (6): 881-885, 2016. 


\title{
اختيار جهاز دانلوب لاستقرار هيمنة العين الحركية بين صغار الإناث السعوديات
}

\author{
المقدمة: اختبار دنلوب موثوق به لتقييم هيمنة العين، ومع ذلك، لم يتم اختبار قابلية تكراره.
}

الهدف من الدراسة: تصديد قابلية اختبار دنلوب لتعديد استقرار العين السائدة وعلى وآثار الجهد البصرى بين الإناث السعويات.

المرضى وطرق البحث: تم تقييم 53 أنثى صحية (تترواح أعمارهم بين 19-23 سنة) لهيمنة العين البصرية والصركية بإستخدام اختبار

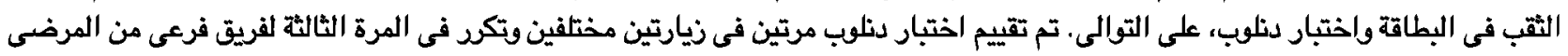

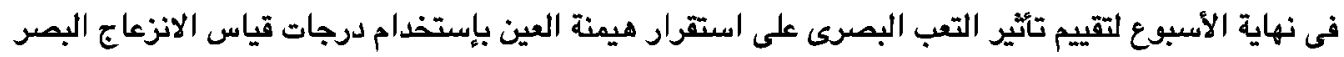

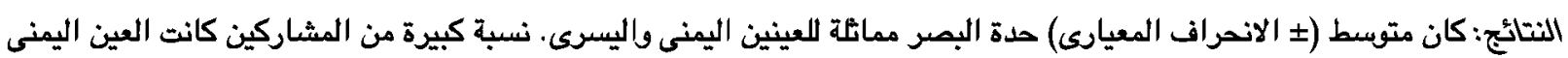

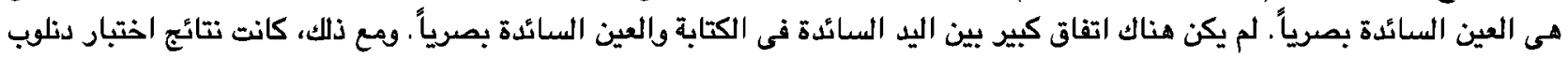

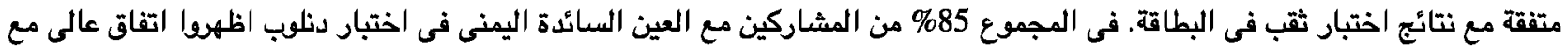

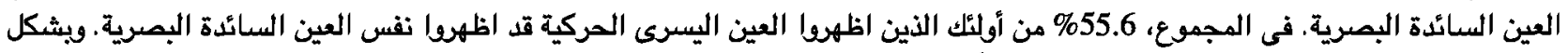

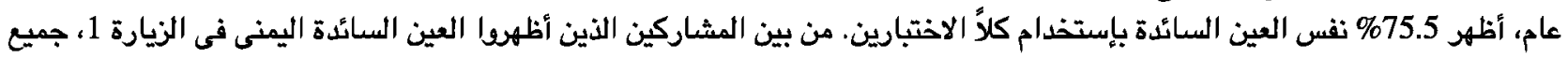

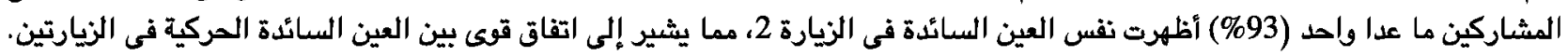

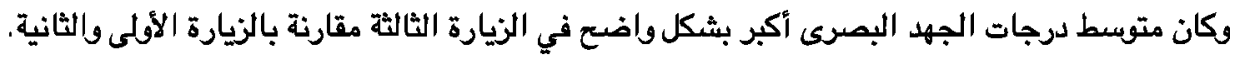

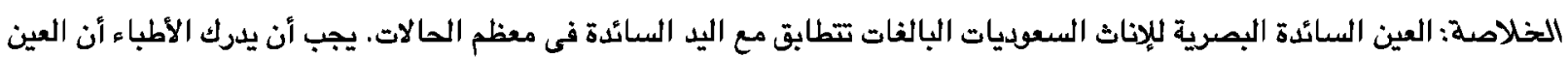

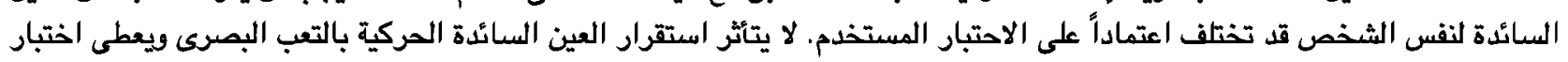
دنلوب نتائج قابلية اللتكرار لتحديد العين السائدة. 